\section{$\underset{\substack{\text { hommes } \\ \text { \& migrations }}}{ }$}

\section{Hommes \& migrations}

Revue française de référence sur les dynamiques

migratoires

$1313 \mid 2016$

1983, le tournant médiatique

\title{
Brigitte Giraud, Nous serons des héros
}

Paris, Stock, 2015, 197 p., 17,50€

\section{Mustapha Harzoune}

\section{(2) OpenEdition}

\section{Journals}

Édition électronique

URL : http://journals.openedition.org/hommesmigrations/3607

DOI : 10.4000/hommesmigrations.3607

ISSN : 2262-3353

Éditeur

Musée national de l'histoire de l'immigration

\section{Édition imprimée}

Date de publication : 1 janvier 2016

Pagination : 172-173

ISBN : 978-2-919040-34-6

ISSN : $1142-852 X$

Référence électronique

Mustapha Harzoune, " Brigitte Giraud, Nous serons des héros », Hommes \& migrations [En ligne], 1313।

2016, mis en ligne le 17 juin 2016, consulté le 24 septembre 2020. URL : http://

journals.openedition.org/hommesmigrations/3607 ; DOI : https://doi.org/10.4000/

hommesmigrations.3607 


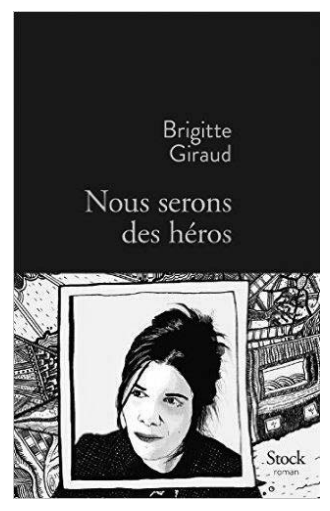

\section{Brigitte Giraud}

Nous serons

des héros

Paris, Stock, 2015,

197 p., $17,50 €$

Dans ce dernier roman, Brigitte Giraud décide de croiser bien des thèmes, bien des univers. Histoire des immigrations portugaise et algérienne, celle des rapatriés d'Algérie, famille recomposée, figure de femme immigrée, ambiguïtés des mémoires, roman de formation pour deux adolescents emberlificotés dans des identités et des mémoires troubles. Elle le fait, par petites touches. Subtiles. Délicates. Lyon. Années 1970. Deux gamins se lient d'amitié. Olivier et Ahmed. Pourquoi cette attirance de l'un pour l'autre? Quel ressort souterrain anime la mécanique de l'attraction dans les cours de récréation? Olivier, c'est Olivio, petit Portugais débarqué avec sa mère fuyant la dictature de Salazar. Ahmed est algérien, hanté par la guerre d'Algérie. Le père de l'un est mort sous la torture des hommes de la Pide, la police politique de Salazar. Le père de l'autre, torturé lui par la soldatesque française, traîne un handicap qui l'empêche de travailler. De cela, Olivio et Ahmed parlent peu. L'auteure livre les informations au comptegouttes, en clair-obscur. Ahmed est hanté, obsédé par la guerre d'Algérie, au point d'imprégner leurs jeux d'une violence qui renvoie aux cruautés de ce conflit : "Nous déchargions la violence qui nous habitait, dit Olivio, nous lut- tions mais nous ne savions pas contre quoi. » Longtemps Olivio n'a rien su de la mort de son père et des conditions de cette mort. Il aura beau en avoir une " intuition »- on ne cache pas les vérités essentielles aux enfants - il apprendra la vérité bien plus tard, trop tard et trop loin, le silence est devenu une faille : "c'est comme si j'étais éternellement décalé ».

À leur arrivée, sa mère et lui ont été aidés par un couple de réfugiés politiques, Luiz et Lydia. Ils habitent un quartier où logent de nombreux rapatriés d'Algérie. Elle y rencontre Max, un pied-noir divorcé, père de Bruno, un fils plus jeune qu'Olivio, dont il a la garde par intermittence. Famille recomposée avant l'heure, les relations y seront difficiles, tendues, "nous nous sentions seuls ma mère et moi, n'étionsnous que des étrangers? ". La mère se fait discrète, doublement invisible, à la maison comme au dehors où, déclassée, baragouinant un français incertain, elle fait des ménages. "Ma mère avait perdu sa légèreté. Mais elle ne voulait pas revenir à l'étape précédente, elle et moi face à face, seuls au monde dans un appartement, dans un pays où nous étions des étrangers. » Dans le couple se joue aussi une guéguerre des mémoires et des paradis perdus : "Leur rencontre s'était faite sur le regret de leurs mondes disparus. C'était leur seconde vie, comme on disait une seconde chance, mais avec une mémoire qui pesait lourd. » Plus lourd encore après la révolution des đillets au Portugal et la possibilité pour les exilés, enfin libres, de retourner au pays. Si le rouge des œillets redonne de la 
couleur et de la fierté à l'immigration portugaise, et singulièrement à la mère et à son fils, Max se moque, lui, d'une révolution pacifique et goûte encore moins le retour en grâce du mari défunt, devenu héros national.

Olivio visitera sa famille au Portugal. Là, il sera exclusivement le fils de son père. Il ressentira la honte de décevoir, la honte de n'être pas à la hauteur du souvenir de ce père, la honte d'être un enfant sensible, bon élève, doué, différent, irréductible aux «nous » dans lesquels, en France comme au Portugal, on voudrait l'enfermer. Avec Ahmed, ils apprennent à devenir les héros de leur propre vie, loin des trajectoires imposées et des injonctions. "Nous n'avions rien à nous reprocher, Ahmed et moi, et pourtant nous nous comportions comme des proies que l'on traque. " Restent les tentatives d'évasion. Même ratées. $M$. H.

\section{Collectif}

Dépasser la frontière
Ker Editions, 2015, 155 pages, 10 E

Que pensent nos concitoyens de la notion de "frontières "? Ceci n'est ni un sondage, ni une étude reposantsur un échantillon précis ì défaut d'être représentatif. Non, it s'agit lì de l'initiative de modestes mais indispen sables bibliothèques ìlaquelle, lecteurs et usagers, ont répondue : un concours d'écriture transfrontière organisé par tes bibliothèques de Beauraing, Biève, Doische, Rochefort et Wellin en Bet gique et Givet dansles Ardennes. Douze eontributions ont été retenues, douze tauréats qui connaissent le privilège d'être publiés. Douze textes quicroisent des univers singuliers, des ambiances plusoumoins denses, desécriturestan tôt scolaires tantôt originales, l'épais seur de la démonstration y eroise le trait, plus subtil et léger, de la fiction. H n'est pas question ici de réfugiés, encore moins d'une Europe-en proie à un délire obsidional. Non. "Dépasser to frontière ", car telest le thème retenu, est d'abord et souvent une expérience personnelle, individuelle, intime même, dont l'écho peut certes retentir audelà dela périphériedes existences. Dequoi s'agit il? D'un traumatisme de l'en fance dont il faudrabien, d'une manière oud'une autre, selibérer. De "frontières qui n'existent qu'à l'intérieur "de ce eomptable retranché, tel un " autiste" derrière un mur bâticomme un refuge, mais qui pourrait céder par amour. B'espace inventé, dans lequel on s'en ferme dans son " ghetto " comme 'a montré Eddy t.Harris (Harlem, Liana tévi, 2007) aupoint d'en devenir l'es elave: "lejardin de Alonsieur Victor, C'est son domaine privé (..) sa dernière raison de vivfe" ! Sacralisationsubjectived'un espace auquel on a parfois consacré une vie entière desacrifices. Alors on le protège, on se protège. Iy y l'instinct dupropriétaire,lesoucidel'ordre et de ta propretéqueles apprentis sorciers de ta politique savent exploiter. Quitte à 